6. Костюк К.Н. Архаика и модернизм в российской культуре [Электронный ресурс]. - Режим доступа: http:// www.nir. $\mathrm{ru} / \mathrm{sj} / \mathrm{sj} / \mathrm{sj} 3-4-99$ kost.html

7. Чистов К.В. Традиция, «традиционное общество»и проблема варьирования // Советская этнография. 1981. — № 2.

8. Лурье С.В. Историческая этнология: учеб. пособие для вузов. - М.: Аспект Пресс, 1997.

9. Яковенко И.Г. Российское государство: национальные интересы, границы, перспективы. - М.: Новый хронограф, 2008.

10. Яковенко И.Г. Познание России: цивилизационный анализ. - М.: Наука, 2008.

11. Кармадонов О.А. Эффект отсутствия: культурно-цивилизационная специфика // Вопросы философии.-2008. - № 2.

12. Дугин А.Г. Археомодерн [Электронный ресурс]. - Режим доступа: http:// www.arcto.ru/article/1472

13. Рязанов А.В. Социокоммуникативные основания и функции современной российской клиентелы // Социокультурные проблемы языка и коммуникации. - Саратов: ПАГС, 2006.

14. Побережников В.И. Переход от традиционного к индустриальному обществу: теоретико-методологические проблемы модернизации. - М.: РОССПЭН, 2006.
15. Ключевский В.О. Курс русской истории // Курс русской истории. Соч. в 9 т. Т. IV. - М., 1989.

16. Яковенко И.Г. Риски социальной трансформации российского общества: культурологический аспект. - М.: Прогресс-Традиция, 2006.

17. Пугачев В.П. Управление свободой. - М.: КомКнига, 2005.

18. Панарин А.С. Стратегическая нестабильность в XXI веке. М.: ЭКСМО; Алгоритм, 2004.

19. Скотт Дж. Благими намерениями государства. Почему и как проваливаются проекты улучшения условий человеческой жизни. - М.: Университетская книга, 2005.

20. Ингиу Оу. Японский менеджмент: прошлое, настоящее и будущее. - М.: Эксмо, 2007.

21. Левинсон А. Кавказ-лаборатория [Электронный ресурс]. - Режим доступа: http:// magazines.russ.ru/nz/ 2012/6/13/html

22. Ламажаа 4.К. Архаизация общества. Тувинский феномен. - М.: Книжный дом; ЛИБРОКОМ, 2013.

23. Словецкий В. Русский язык в Тыве стал иностранным [Электронный ресурс]. - Режим доступа: http:// www.svpressa. ru/society/63983/

24. Рязанов А.В. Управление идентичностью: артикуляция этнокультурных границ в полиэтничных регионах России // Власть. - 2012. — № 4.

\title{
Р.К. ТАНГАЛЫЧЕВА
}

\section{АККУЛЬТУРАЦИЯ ВРЕМЕННЫХ МИГРАНТОВ ИЗ ЗАРУБЕЖНЫХ СТРАН В КРУПНОМ РОССИЙСКОМ ГОРОДЕ}

Рассматриваются вопросы межкультурной коммуникации и аккультурации иностранцев в крупном городе, анализируются различные подходы к изучению аккультурации и крупного города как пространства межкультурной коммуникации. Утверждается, что решение проблем аккультурации и преодоления трудностей, возникающих у иностранных граждан в процессе приспособления к инокультурной среде, возможно на основе техники культурного ассимилятора. Пространство крупного города рассматривается на примере Санкт-Петербурга, с самого основания поликультурного города.

Ключевые слова: межкультурная коммуникация, аккультурация, временные мигранты, крупный город, глобализация, техника культурного ассимилятора.

B условиях глобализации миллионы людей, принадлежащих к разным культурам и социальным группам, получили возможность свободно перемещаться по миру и участвовать в культурных практиках других народов. Местами локализации их межкультурных контактов в настоящее время являются крупные города, так как именно они представляют собой центры культурного разнообразия, развитой инфраструктуры и социальных возможностей. Некоторые зарубежные и российские города приобрели в последнее время глобальные черты, привлекая новых участников межкультурных обменов персонал международных компаний и организаций, дипломатических служб, студентов, туристов, а также вынужденных трудовых мигрантов и членов их семей.

В крупнейших российских городах численность временных мигрантов из зарубежных стран достаточно велика и постоянно растет. Процесс их вовлечения в принимающее общество усложняется тем, что они, в конечном счете, или возвратятся домой, или отправятся в другую страну. Поэтому они обычно находятся в ситуации выбора между 
желанием полностью включаться и устанавливать близкие отношения с местным населением и желанием дистанцироваться от социального и культурного окружения.

Интенсивные межкультурные контакты неизбежно расширяют картину мира и релятивизируют идентичность участников международного сотрудничества. Принимающая культура и ее городское пространство оказывают сильное влияние на поведение и восприятие «новичков». Цели эффективного взаимодействия диктуют необходимость приспособления к новым условиям. Вместе с тем процесс приспособления носит двусторонний характер представители принимающей культуры под воздействием инокультурных влияний тоже изменяют свои исходные характеристики. Этот процесс взаимовлияния получил название аккультурации.

Согласно определению Р. Редфилда, Р. Линтона и М. Херсковица, аккультурация «охватывает собою те явления, которые возникают в результате вхождения групп индивидов, обладающих разными культурами, в непрерывный непосредственный контакт, вызывающий последующие изменения в изначальных культурных паттернах одной из групп или их обеих» [1, р. 149]. В 1901 году социолог С. Симонс опубликовала обзор исследований аккультурации в XIX веке. Большинство работ того времени принадлежало европейским социологам. Все они доказывали обоснованность «взаимного приспособления», приведшего к культурному слиянию (поглощению) в мультикультурных империях или современных национальных государствах. В немецкой литературе этот процесс получил название амальгамизация, а англоязычной - ассимиляция. С. Симонс пишет: «Это может быть определено как процесс приспособления, который происходит между членами двух различных рас, в случае, если контакт был продолжительным и если в нем присутствовали необходимые психические условия. Результатом подобного контакта являлось достижение относительной групповой гомогенности. Фигурально выражаясь, это процесс, благодаря которому совокупность людей изменяется от простого механического соединения до сложного химического» [2, р. 791-792]. Несмотря на очевидность того факта, что аккультурация влечет за собой двусторонние процессы изменений, дальнейшие исследования в этой области сфокусировались на приспособлении и изменениях, происходящих в группах аборигенных людей, иммигрантов, «визитеров» и других культурных меньшинств в результате их контактов с доминирующим большинством.

Из определения аккультурации мы можем выделить некоторые ключевые элементы, которые обычно анализируются в кросскультурной коммуникации. Во-первых, необходимо, чтобы имелся постоянный и непосредственный контакт или взаимодействие между культурами: это исключает кратковременные, случайные связи и распространение (диффузию) практик одной культуры на дальние расстояния. Во-вторых, результатом является некоторое изменение культурных и психологических феноменов среди людей, которые находятся в контакте; обычно это продолжается и в течение жизни последующих поколений. В-третьих, если сочетать два этих аспекта, мы можем провести различие между процессом и состоянием: проявляется активность во время и после контакта, который носит динамический характер. Имеет место также долговременный результат процесса, который может быть относительно стабильным и включать не только изменение существующих феноменов, но также и некоторые новые явления, возникающие в результате процесса культурного взаимодействия.

Иногда аккультурация может рассматриваться как процесс культурного обучения, навязывающего группам меньшинств факт их принадлежности к меньшинствам. Если инкультурация представляет собой обучение первой (родной) культуре, то аккультурация - обучение второй (чужой) культуре. Этот процесс часто преподносится как бесконфликтный культурный обмен, в ходе которого культура меньшинств вытесняется культурой доминирующего большинства, то есть происходит простая ассимиляция. Однако термины ассимиляция и аккультурация имеют разную трактовку. Если ассимиляция означает полное растворение личности в инокультурной среде, то аккультурация предполагает разные стратегии приспособления к новым условиям существования.

Начиная с середины XX века аккультурацию трактуют как стратегию реагирования меньшинства на продолжительный контакт с доминирующей группой. Существует несколько стратегий приспособления групп меньшинств, каждая из которых основана на разных мотивациях и последствиях. Эти стратегии включают ассимиляцию в культуре большинства, защитное утверждение группы меньшинства, бикультурное смешивание двух культур, бикультурное изменение культур в зависимости от контекста или ослабление двух культур. Дж. Берри [3, 4] предложил четыре основные стратегии аккультурации - ассимиляция, сепарация, интеграция и маргинализация. Психологические, соматические и социальные трудности, сопровождающие процесс аккультурации, называют «стрессом аккультурации». Первыми обратили внимание на «психический конфликт», возникающий на основе конфликта культурных норм, Р. Редфилд, Р. Линтон и М. Херсковиц. Дж. Берри разработал концепцию, согласно которой стресс аккультурации - это фундаментальная психологическая сила в процессе аккультурации. Позднее были предприняты попытки измерить стресс аккультурации, и многие исследователи с тех пор утверждают, что он представляет собой важнейшую проблему для многих групп меньшинств.

Аккультурация может иметь разнообразные формы проявления. В случае длительных контактов культуры обмениваются образцами питания, музыкального и танцевального искусства, одежды, орудий труда и технологий, и происходит процесс культурного смешивания. В рамках определения термина аккультурация проводится различие между индивидуальной транскультурацией и групповой, обычно охватывающей большое число участников. Транскультурация, или индивидуальная аккультурация мигрантов к культуре большинства, представляет собой менее значимый процесс, поскольку она происходит в меньшем масштабе и с менее заметными последствиями. 
Чаще всего она связана с приспособлением иммигрантов в первом поколении, так как именно для них аккультурация является наиболее сложной в силу недостатка семейного опыта. Скорость транскультурации зависит от интересов реципиентов (новичков, осваивающих культуру) и наличия мотивации. Другим примером аккультурации можно признать опыт путешественников за границей, которые могут «схватывать», допустим, какую-то новую региональную специфику, особенно если их язык относится к родственной языковой группе.

Рассматривая аккультурацию временных мигрантов в Санкт-Петербурге, мы исходили из того, что проблемы порождает не только разница этнических или национальных культур участников взаимодействия, но и специфика социального пространства такого крупного города, как Петербург, выступающего центром притяжения самых разнообразных материальных, символических и человеческих ресурсов.

Санкт-Петербург - четвертый по численности город Европы (после Стамбула, Лондона и Москвы) и самый северный город с населением более миллиона человек. По состоянию на 2012 год численность населения города составила 5 млн человек [5]. Все черты городского образа жизни, свойственные современным городам, присущи и Санкт-Петербургу. Можно даже сказать, что они носят еще более явно выраженный характер по сравнению с городами меньшего масштаба и значения. Вместе с тем Санкт-Петербург обладает рядом специфических черт, выделяющих его из множества других городов: культурно-историческая уникальность и специфический состав населения, определяемый характером миграции в город из других населенных пунктов и из-за рубежа. Также нельзя не отметить определенных веяний глобализации и интернационализации, которые воздействуют на город и его жителей в последние десятилетия.

Материалом, из которого традиционно складывается образ Петербурга, является его культура (а не промышленность или, тем более, некий промысел). Культуру Санкт-Петербурга можно трактовать как тему, можно как реальность регионального характера, как особый текст с его специфическим языком [6, с. 179]. Семиотический подход к культуре Санкт-Петербурга позволяет рассматривать его культуру как существующий в контексте текст, определение которого зависит от избираемой идеологии. Сегодня Петербургу предложено две альтернативных идеологемы: московская - культурная столица России - и европейская - «окно в Европу» [6, с. 178]. Вместе с тем нельзя не отметить, что за свою историю Санкт-Петербург поменял несколько названий-эпитетов, вольно или невольно отражавших попытки сформировать его имидж. Среди наиболее популярных: «Северная Венеция», «Северная Пальмира», которые подчеркивают архитектурно-градостроительные особенности города, служившие оценкой его привлекательности; название «Город трех революций» свидетельствует о происходивших здесь важных исторических событиях; в последние годы - «Северная столица».
Санкт-Петербург обладает значительным историкокультурным наследием для формирования туристического продукта и продвижения его на внутреннем и внешнем рынках, для превращения туризма в базовую отрасль городской экономики. Высокая привлекательность СанктПетербурга как туристического центра обусловлена объективными факторами. Архитектурный ансамбль города и его окрестностей XVIII-XIX веков сохранился в практически неизменном виде. По разным причинам СанктПетербург сегодня превратился в уникальный заповедник европейских архитектурных стилей трех последних столетий. Этому, в частности, способствовала утрата городом столичного статуса, которая в значительной степени предотвратила вторжение в архитектурный облик исторического центра зданий стилистики середины - конца XX столетия. Не случайно именно в Санкт-Петербурге активно проявили себя общественные движения против строительства 400-метровой башни «Газпрома» напротив Смольного собора. Этот проект, по мнению многих защитников города, несет угрозу историческому облику Санкт-Петербурга.

В 2012 году Санкт-Петербург посетили около 2,9 млн иностранных туристов. Всего, с учётом российских туристов, город посетило более 6 млн человек [5]. По сведениям Северо-Западного пограничного округа, в 2003 году Санкт-Петербург и Северо-Западный регион России посетило 3112632 иностранных граждан из 190 стран, что на 13,7 \% больше показателя 2002 года. Наибольшее число въезжающих - туристы (60\%), с частной целью въехало $16 \%$, с коммерческой - $7 \%$, с деловой $-7 \%$, на работу - $4 \%$, на учебу - $2 \%$ иностранцев. В эти данные не входят посещения СанктПетербурга иностранными гражданами, прибывающими в город через другие участки границы РФ, а также около 800 тыс. внутрироссийских туристов. Основная масса туристов, посетивших Санкт-Петербург в 2006 году, прибыла из: ФРГ - ок. 50 тыс. чел.; Италия - ок. 47 тыс. чел.; Финляндия - ок. 46 тыс. чел.; США - 40,5 тыс. чел.; КНР - ок. 38 тыс. чел.; Франция - 28 тыс. чел.; Великобритания - 27,5 тыс. чел.; Япония - ок. 25 тыс. чел. [7]. В последние годы в числе стран-лидеров по числу иностранных туристов в городе - Китай, Индия, Южная Корея и Япония [5].

Как отмечают исследователи города, Петербург был и в значительной мере остается своего рода «плавильным котлом», тиглем, где переплавлялись и превращались в петербуржцев представители других регионов России и зарубежья, постоянно вливавшиеся в его население. Петербург - один их тех городов мира, которые оказывают на своих обитателей исключительно сильное воздействие. Рельеф местности, особенности регулярной планировки и классической архитектуры, климат, мощный пласт культурного наследия. Традиционная роль проводника европейской культуры в Россию - все это в совокупности образует неповторимую среду обитания, сущность Петербурга. Мощное моделирующее воздействие городского пространства исторического центра Петербурга 
признается всеми. Новые жители, к которым относится подавляющее большинство населения, совсем не чувствуют себя чужими в Петербурге - Ленинграде и смело идентифицируют себя с ним [8, с. 100].

Петербург, подобно Москве и большинству других крупных европейских городов, всегда был городом приезжих. С конца XIX века коренные петербуржцы составляли менее трети населения города. И городское население в целом, и рабочий класс столицы росли благодаря крестьянской миграции. Со времени отмены крепостного права крестьяне составляли все более возрастающую долю населения Петербурга [8, с. 86].

Иностранцы появились в Санкт-Петербурге с момента его основания. Основную массу их составляли приглашенные царем Петром I специалисты (военные, моряки, ученые, ремесленники). Выходцы из стран Европы занимали различные посты в сфере государственного управления, в армии и флоте, играли заметную роль в сфере наук и искусств, были хозяевами фабрик и заводов, торговцами, ремесленниками. Среди них преобладали немцы, далее по численности следовали французы, англичане. Проживали в городе также шведы, голландцы, итальянцы. В 1750 году в Санкт-Петербурге насчитывалось около 5,6 тыс. иностранцев (7,5 \% населения), в 1818 году - примерно 35 тыс. (9\%). К середине XIX века доля иностранцев в составе населения Санкт-Петербурга сокращалась при незначительном изменении общей численности: в 1869 году - 21,1 тыс. чел. (3,16\%), в 1910-м - 22,9 тыс. чел. (1,2\%). Пребывание значительного числа иностранцев отражалось в облике его улиц (вывески на иностранных языках, культовые здания и пр.). Резкое сокращение численности иностранцев, постоянно проживавших в городе, произошло после октября 1917 года. Практически все общины, состоявшие из иностранных граждан, прекратили свое существование. Рост численности иностранцев вновь отмечен в 1990-х. К 2001 году в Санкт-Петербурге постоянно проживали свыше 2 тыс. иностранцев (без учета нелегальных иммигрантов и беженцев) $[9,10,11]$. В настоящее время их число возросло многократно.

Сегодня в этом российском мегаполисе также представлено множество национальностей и все основные мировые конфессии. Национальные диаспоры СанктПетербурга внесли большой вклад в его развитие и в настоящее время глубоко интегрированы во все сферы жизни города, являются неотъемлемым компонентом современного гражданского общества не только города, но и России в целом. По данным Всероссийской переписи населения 2002 года, 15,3 \% населения города (около 711600 чел.) составляют нерусские. Согласно международным нормам город считается многонациональным, если кроме основной национальности совокупное население всех остальных проживающих составляет не менее 5 \%. В Петербурге всегда численно преобладали русские, однако столь же постоянным было присутствие представителей десятков иных национальностей (от 6 до $23 \%$ населения) [12].

Санкт-Петербург в последние годы постепенно приоб- ретает черты глобального мегаполиса: растет число генеральных консульств иностранных государств, открываются иностранные и совместные компании, культурные центры, учреждения, представительства государственных и негосударственных фондов и организаций, международные образовательные программы и т. д. В Санкт-Петербурге прочно обосновались всемирно известные иностранные компании. Среди них выделяются следующие: автомобильные заводы «Toyota», «Nissan», «General Motors». «Hyndai»; завод по производству бытовой техники «Bosch und Siemens Hausgerate $\mathrm{GmbH»,} \mathrm{завод} \mathrm{по} \mathrm{производству} \mathrm{гипсокартонных}$ листов «Knauf», завод по производству телекоммуникационного оборудования «Elcoteq», завод по розливу прохладительных напитков «РерsiCo», завод по производству бритвенных станков «Gillette» [13].

В городе действуют генеральные консульства 54 стран, обучается около 20 тыс. иностранных студентов. Очевидным признаком интернационализации образования является тот факт, что согласно Программе развития Санкт-Петербургского государственного университета до 2020 года доля образовательных программ и учебных дисциплин, преподаваемых на иностранных языках, должна быть не менее 20 процентов [14]. Вместе с тем необходимость экономического развития привлекает в город не только инвесторов и высококлассных специалистов, но и трудовых мигрантов, без которых представить современное развитие в России уже невозможно.

Таким образом, особая социокультурная среда города не только способствует включению в социокультурное поле вчерашних мигрантов, но и воздействует на мировосприятие и поведение иностранных граждан, которые живут и работают в Санкт-Петербурге. Тем не менее, гармоничная коммуникация между представителями разных культур и доминирующим большинством в тех или иных «сеттингах» (бизнес, образование и др.) остается во многом лишь благим пожеланием. Людям, выросшим и сформировавшимся в разных социокультурных средах, сложно приспособиться к ожиданиям и требованиям друг друга. Одним из способов решения проблем аккультурации и приспособления временных мигрантов из зарубежных стран в российском мегаполисе является тренинг по технике культурного ассимилятора.

Первые культурные ассимиляторы были разработаны в начале 1960-х годов американскими психологами и антропологами под руководством Г. Триандиса. В 1980-е годы благодаря исследованиям Р. Брислина и К. Кушнера появилась идея общего культурного ассимилятора, способного помочь людям адаптироваться к любой инокультурной среде.

Р. Брислин с соавторами выделяют восемнадцать проблем, с которыми обычно сталкиваются мигранты в период адаптации. Ситуации, отражающие эти проблемы, были сгруппированы ими в три более широких раздела:

- интенсивные эмоциональные реакции (тревожность, несбывшиеся ожидания, ощущение недостатка эмоциональной поддержки со стороны местных жителей, неопределенность отношений с ними, борьба с собственными предубеждениями и этноцентризмом); 
- сфера знаний, важных для понимания межкультурных различий (социальные установки на труд и собственность; пространственно-временная организация общения; отношение к иностранным языкам; ролевые структуры; индивидуализм/коллективизм; ритуалы и суеверия; иерархические структуры - классовые и статусные; личностные и социальные ценности);

- когнитивные психологические процессы и явления, лежащие в основе межгрупповых различий (категоризация, дифференциация, этноцентризм, атрибуция, стиль приобретения знаний) [15].

Метод общего культурного ассимилятора обучает тому, как адекватно относиться к различиям (формировать «корректные» ожидания), с которыми иностранцы сталкиваются в новой культурной среде. Эти различия могут касаться отношений людей на работе, способов профессионального и социального взаимодействия, восприятия времени и пространства, языковых отличий, реакции на иерархические отношения и различия в ценностях.

Культурный ассимилятор представляет собой короткую историю взаимодействия представителей двух четко разделяемых культур, в процессе которого участники сталкиваются с определенной проблемой. Каждая история сопровождается 4-5 альтернативными вариантами решения проблемы и просьбой выбрать наиболее подходящий ответ. Также к каждому варианту ответа дается экспертная интерпретация этих ответов, только один из которых является верным. Тренинг по методу культурного ассимилятора включает от 100 до 150 таких коротких историй и предназначен для индивидуальной или групповой работы с брошюрой либо компьютерной программой. После работы с культурными ассимиляторами новички (представители гостевых культур) начинают лучше понимать субъективную культуру принимающей стороны и, следовательно, реагируют более или менее адекватно на ее проявления.

Предложенные Р. Брислином с соавторами темы для общего культурного ассимилятора были модифицированы и использованы в ряде исследований, посвященных: мультикультурному образованию преподавателей; обучению молодежи; подготовке специалистов в области здравоохранения, бизнеса, социальной работы, дипломатов и др.; тренингам для глухонемых; тренингам для участников арабо-еврейских отношений; подготовке космонавтов по программе НАCA.

Для повышения успешности аккультурации в крупном российском городе на факультете социологии СанктПетербургского государственного университета был разработан тренинг повышения межкультурной восприимчивости для адаптации к жизни в Санкт-Петербурге. Он включает 139 критических ситуаций взаимодействия временных мигрантов с петербуржцами в таких сферах, как бизнес, образование, пространство города, дом, семья, досуг, развлечения, услуги, обслуживание. Тренинг по методике культурного ассимилятора воздействует на когнитивную, эмоциональную и поведенческую составляющие социальных установок временных мигрантов. Аккультурация - это процесс двусторонних изменений, следовательно, этот тренинг может быть полезным и для горожан - жителей крупных городов, вступающих в деловые и повседневные контакты с иностранцами [16].

\section{Список литературы}

1. Redfield R., Linton R., Herskovits M. J. Memorandum for the study of acculturation // American Anthropologist. 1936. - Vol. 38.

2. Simons S.E. Social assimilation // American Journal of Sociology. - 1901. - Vol. 6.

3. Berry J.W. Acculturation as Varieties of Adaptation // A. Padilla (ed.), Acculturation: Theory, Models and Some New Findings. - Boulder: West-view, 1980.

4. Berry J.W. Conceptual Approaches to Acculturation. In K. Chun, P. Balls-Organista, G. Marin (eds.), Acculturation: Advances in Theory, Measurement and Applied Research. Washington: APA Books, 2003.

5. Количество туристов, посетивших Петербург за 2012 год, превысило число жителей города / Петербург сегодня. Городские новости. 15.04.2013 [Электронный ресурс]. Режим доступа: http://sptoday.ru/2013_04_15/kolichestvoturistov-posetivshix-peterburg-za-2012-god-prevysilo-chislozhitelej-goroda/

6. Дамберг С.В., Семенков В.Е. Провинциальный город СанктПетербург: символический капитал в мире искусства // Журнал социологии и социальной антропологии. -2000. — № 3.

7. Проблемы миграции. Материалы Комитета по труду и социальной защите населения [Электронный ресурс]. — Режим доступа: http://www.vd-spb.ru/

8. Марголис А. Феномен «коренного» петербуржца: мифы и реальность / Город и горожане в России XX века. Материалы российско-французского семинара. - СПб., 2001.

9. Лурье Л. «Питерщики» в Петербурге / Город и горожане в России XX века. Материалы российско-французского семинара. - СПб., 2001.

10. Юхнева Н. В. Этнический состав и этносоциальная структура населения Петербурга, вторая половина XIX - нач. XX в.: стат. анализ. - Л., 1984.

11. Многонациональный Петербург. История. Религия. Народы / под науч. ред. И.И. Шангина. - СПб.: Искусство, 2002.

12. Национальные школы: гетто или диалог культур [Электронный ресурс]. - Режим доступа: http://www.narodru.ru/

13. Крупнейшие иностранные компании, инвестирующие в экономику Санкт-Петербурга / Официальный портал Администрации Санкт-Петербурга [Электронный ресурс]. - Режим доступа: http://gov.spb.ru

14. Программа развития федерального государственного образовательного учреждения высшего профессионального образования «Санкт-Петербургский государственный университет» до 2020 года [Электронный ресурс]. - Режим доступа: http://www.spbu.ru/structure/

15. Brislin R.W., Cushner K., Cherrie C., Yong M. Intercultural interactions: A practical guide. - Beverly Hills, CA: Sage, 1986.

16. Культурный ассимилятор. Тренинг адаптации к жизни в Санкт-Петербурге / отв. ред. Р.К. Тангалычева и Н.А. Головин. - СПб., 2009. 